\title{
Policing in the pandemic: an investigator's perspective
}

\author{
Simon Foy ${ }^{1}$ QPM
}

As the pandemic began to take hold of the nation's consciousness in the early Spring of 2020 , it forced a fundamental change in both attitude and behaviour in a public that became increasingly distressed by the enormity of what was upon them. How we lived our lives changed, our simple daily habits had to be adapted to the 'new' reality. In an attempt to both try and rationalise what was happening and think though what the next steps to cope with it would be, social commentators, journalists, politicians and academics were all amongst the groups of people who engaged in efforts to seek to understand the true impact of the pandemic.

Crime and criminality were one of the many topics in the debate. The more obvious and immediate consequences became clear. Residential burglary would change by nature and volume almost instantly in line with the simple consequence of more people being in their homes for extended periods in the day. Restrictions on movement, gatherings, travel and association inhibited the availability of potential victims of different types of street violence. Those who understand and worry about the insidious nature of domestic violence within the home were anxious to point out the clear potential of the increased risk to victims who were now legally obliged to inhabit the environment of those who sought to hurt and harm them.

Policing as a profession was also quickly drawn into the debate as well. There was a robust political and social debate about what the role of police should be in enforcing the regulatory requirements that restricted people's ability to move about. There seemed to be strong public and political support to 'enforce the rules' against those who broke them. The issue of the potential disproportionate impact of this enforcement activity on minority communities became immediately apparent. Policing by consent and the use of discretion became more difficult to apply. The summer of Black Lives Matter protests (sparked of by an incident in the USA) added an additional layer of emotion and anger to what was already a challenge to the perception of the police as being 'fair'. Political and media speculation bore down on the decision-making processes in police forces across the country, and subjected them to intense scrutiny and criticism. The cautious and careful positioning by Durham Constabulary in their dealing with a well-known individual's journey to the county and Derbyshire Constabulary's dilemma in what to do after issuing a fine to people who claimed to be out for a walk are just two of many different examples of the tone and highly reactive nature of the scrutiny of police and policing.

Now, one year on, it seems as if the debate is at least based on some semblance of analysis of the evidence and data, and the learning as to what happened, and what to do next, is more measured. A recent analysis ${ }^{2}$ has looked at the shifts in criminality and criminal behaviour over a full year. The criminal justice system is, it seems, working out how to deal with the backlog of cases by focusing on solutions that are more upstream and consequential, rather than just simply increasing court capacity. It is this type of approach and thinking that will help us to understand both what happened in this year of the pandemic, and also, crucially, what it has meant to the agencies charged with dealing with crime and criminality and discharging their vital duty of keeping communities safe.

It seems appropriate, therefore, that this is also a time to think through how the changes will impact on the way that crime is investigated. It is now necessary to consider what this new reality means and crucially adapt and change to deal with it. To illustrate this, 
I am going to use three separate and distinct examples, which all illustrate the same point - the way that police investigate will need to be different. The difference demands a potentially more subtle and agile approach to practice and procedure.

Reduced physical interaction by caring, voluntary and statutory agencies with families who are at risk, and particularly with vulnerable children and adults, is a direct consequence of the current times. The opportunity to interface with those at risk has been reduced considerably by the needs to keep both the staff of the agencies and their clients safe. There has been an exponential growth in contact being made virtually. ${ }^{3}$ It has been increasingly difficult, for example, to be able to speak directly to a potential victim of domestic violence in a home setting, given that the perpetrator might well be present in the same room. These interactions have become much more sophisticated over time with innovative thinking and planning overcoming some of the risk. The reduced 'eyes-on' contact is, however, still a significant risk.

The ever-shifting pattern of cyber-enabled fraud has been part of the continued and sustained growth of this crime. New types of fraud are identified regularly and surges in dating/romance fraud and investment fraud have spiked as more people are drawn into the virtual environment, this being their only means of communication with the world at large. ${ }^{4}$ They are targeted and victimised and their vulnerability through sustained online activity has added yet another unique element to the victimology of this type of crime.

The National Crime Agency identified in the early days of the pandemic that organised crime groups and networks have recognised and exploited the shift in public behaviour and has changed the location and nature of street markets for low-level drug dealing. ${ }^{5}$ It can be seen in the new phenomenon of dealers infiltrating the queues and gathering around shops and car parks; disguising themselves as key workers; and in the behaviour of young people, who have continued to associate outside despite the restrictions of their being able to do so, forcing a change to the 'county lines' distribution networks. It is an age-old reality - the way that people gather, associate and where they do it is a constant source of potential exploitation for those seeking to create an environment to deal in illegal drugs. The period of the pandemic is no different - it just has its own unique patterns.

In each of the examples above there is a clear and widespread understanding that they are real and happening now. The case has been made to do something and the dedicated professionals charged with this action are, as ever, quietly getting on with it. The investigative paradigm has to adjust and change. I suggest that there is a more subtle change now needed in investigative doctrine as well. The way that we deal with this is crucial. It will not be easy. There will be a vigorous public response when one of these scenarios above results (as it tragically is absolutely certain to) in the death or injury of a vulnerable victim that captures the public's attention. Reactive political response will almost certainly follow as the need to 'be seen to do something' and manage perception comes to the fore of political leaders' thinking. Embedding carefully considered new practice, in a grounded and sustained way, across a wide range of investigating agencies will not suffice as a response when there is a demand to ask what is being done about this latest cause for concern.

In my experience, the best and most effective way to ensure that investigators can get on with what they need to do, in the pressure cooker environment of operating under intense public gaze and scrutiny, is to have clear principles and guidance that they can adhere to and (as a separate issue for consideration elsewhere) have strong, measured and supportive leadership around them. So, using the examples that I have given above, I would suggest the following need to be translated into doctrine, which can then influence operational practice:

1. As a matter of routine, the weight and categorisation of intelligence and information around families and children at risk needs to take into account how much of it has been gained through actual 'face to face' contact (by the whole range of agencies 
Vol. 8, No. 1, 139-141.

involved), as opposed to virtual communication by phone or other types of media. Agencies (including police) are now recognising the risks that have been caused by not physically seeing a vulnerable child/adult. Extra care needs to be taken when making decisions based on information/intelligence gained during the period when this 'gap' has occurred.

2. Understanding the vulnerability of victims of new types of fraud becomes more significant in recognising and understanding the reasons why they are preyed upon by criminals perpetrating this constantly changing and evolving crime type. The insight given by gathering analysis of why victims were targeted is a fundamental part of a 'prevent and protect' strategy to deal with the increasing crime levels, particularly as the sheer dynamism and relentless innovation in the criminal behaviour of fraudsters will always leave the 'pursue' tactics struggling to keep pace with how things are changing.

3. As low- and street-level drugs markets change and adapt to how and where people gather, the intelligence gathering exercise, which will inform any enforcement activity, needs to change too. A completely different type of process will need to be followed, whether it be in the deployment of covert tactics to understand the nature of the markets themselves, to the sources of intelligence and information around them, and the type, nature and deployment of low-level 'buy/bust' operations or disruptive, intelligence-led stop and search activities.

The three examples used above are relatively random, address different issues, and are just a few of many subtle changes that the new reality of the pandemic is presenting to the way that crime is addressed and dealt with. They are, however, indicative of the need for a shared objective for policing in 2021 and beyond, delivering smart, agile, evidence-based tactics to support a flexible investigative approach to deal with the risks and challenges of the new reality. The same public, whose sentiment I began this article with, and who are perplexed and anxious about their safety, expect and deserve nothing less.

\section{Notes}

${ }^{1}$ After graduating in Law from Queen Mary College, University of London in 1982, Simon Foy joined the Metropolitan Police Service. As an associate of the College of Policing, he worked on the Strategic Command Courses of 2013 to 2015; courses developing senior officers' understanding and role within serious crime incidents; and latterly working with the Serious Fraud Office in a series of courses to develop their investigative thinking. He has been involved in the design, set up and implementation of a specialist unit within Action Fraud to support vulnerable victims of fraud. He has expertise in the application and relevance of the principles of policing by consent to other jurisdictions.

simoncfoy@gmail.com

${ }^{2}$ Crest Advisory: Danny Shaw examines todays crime stats -3/2/21. Available at: https://www.actionfraud. police.uk/fauxmance.

${ }^{3}$ Social Care Institute for Excellence (SCIE): Safeguarding children and families during the COVID-19 crisis - updated 7/1/21. Available at: https://www.actionfraud.police.uk/fauxmance.

${ }^{4}$ Action Fraud: Romance Scams on the up during Lockdown - Alert 10/2/21. Available at: https://www. actionfraud.police.uk/fauxmance.

5 The Independent: Coronavirus: Drug dealers 'disguising themselves as key workers' during UK lockdown (quote from NCA Director Lynne Owens) - 15/4/20. Available at: https://www.independent.co.uk/news/ uk/crime/coronavirus-drug-dealers-key-workers-uk-lockdown-police-fines-a9466526.html. 